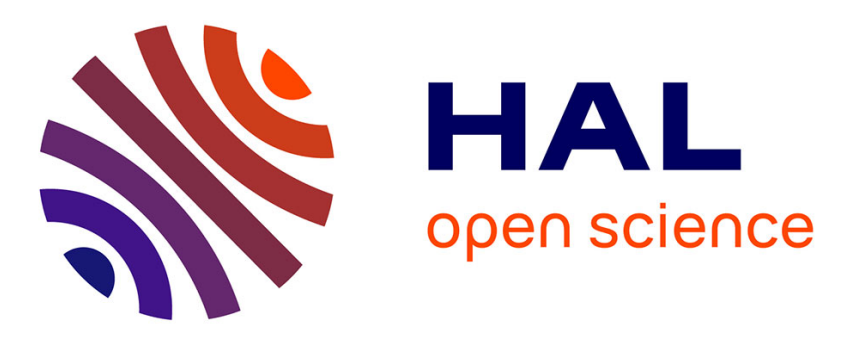

\title{
Rheology and phase behavior of dense casein micelle dispersions
}

\author{
Antoine Bouchoux, Belkacem Debbou, Geneviève Gésan-Guiziou, \\ Marie-Hélène Famelart, Jean Louis Doublier, B. Cabane
}

\section{To cite this version:}

Antoine Bouchoux, Belkacem Debbou, Geneviève Gésan-Guiziou, Marie-Hélène Famelart, Jean Louis Doublier, et al.. Rheology and phase behavior of dense casein micelle dispersions. Journal of Chemical Physics, 2009, 131, pp.1-11. 10.1063/1.3245956 . hal-01454089

\section{HAL Id: hal-01454089 \\ https://hal.science/hal-01454089}

Submitted on 19 Apr 2019

HAL is a multi-disciplinary open access archive for the deposit and dissemination of scientific research documents, whether they are published or not. The documents may come from teaching and research institutions in France or abroad, or from public or private research centers.
L'archive ouverte pluridisciplinaire HAL, est destinée au dépôt et à la diffusion de documents scientifiques de niveau recherche, publiés ou non, émanant des établissements d'enseignement et de recherche français ou étrangers, des laboratoires publics ou privés. 


\title{
Rheology and phase behavior of dense casein micelle dispersions
}

\author{
A. Bouchoux, ${ }^{12,2}$ B. Debbou, ${ }^{12}$ G. Gésan-Guiziou, ${ }^{12}$ M-H. Famelart, ${ }^{12}$ J-L Doublier, ${ }^{3}$ and B. Cabane ${ }^{4}$ \\ 'INRA, UMR1253, STLO, F-35042 Rennes, France \\ ${ }^{2}$ AGROCAMPUS OUEST, UMR1253, F-35042 Rennes, France \\ ${ }^{3}$ INRA, UR1268, BIA, F-44316 Nantes, France \\ ${ }^{4} \mathrm{PMMH}, \mathrm{CNRS}$ UMR7636, ESPCI, F-75231 Paris cedex 05, France \\ "Electronic mail: antoine.bouchoux@rennes.inra.fr
}

\begin{abstract}
The rheology of casein micelle dispersions that have been concentrated through osmotic stress is reported. In conditions where the casein micelles are separated from each other, i.e. below random-close packing, the dispersions have exactly the flow and dynamic properties of the polydisperse hard-sphere fluid, demonstrating that the micelles interact only through excluded volume effects in this regime. These interactions cause the viscosity and the elastic modulus to increase by 3 orders of magnitude approaching the concentration at random-close packing, estimated at $C_{\max } \approx 178 \mathrm{~g} / \mathrm{L}$. Above $C_{\max }$, the dispersions progressively turn into "gels" (i.e. soft solids) as $C$ increases, showing elastic moduli $G^{\prime}$ measured at low strains that are nearly frequency independent. In this second regime, the micelles deform and/or deswell as $C$ increases and the resistance to deformation results from the formation of bonds between micelles combined with the intrinsic mechanical resistance of the micelles. The variation of $G^{\prime}$ with $C$ is then very similar to that observed with concentrated emulsions where the resistance to deformation originates from a set of membranes that separate the droplets. As for emulsions, the $G^{\prime}$ values at high frequency are also nearly identical to the osmotic pressures required to compress the casein dispersions. The rheology of sodium caseinate dispersions in which the caseins are not structured into micelles is also reported. Such dispersions have the behavior of common attracting polymer solutions at all the concentrations investigated; further confirming the importance of structure in determining the rheological properties of casein micelle systems.
\end{abstract}




\section{INTRODUCTION}

Caseins make up to $80 \%$ of the protein content of cow milk. In native milk, they are associated into large aggregates that are called casein micelles. These "micelles" contain the four caseins $\alpha_{\mathrm{s} 1}, \alpha_{\mathrm{s} 2}, \beta$, and $\kappa$ in proportion of 3:1:3:1, and $\sim 8 \%$ in mass of phosphate and calcium ions. Their main biological function is the transport and delivery of proteins and essential minerals to the young mammals. ${ }^{1}$ The structure of the casein micelles have been studied for over 40 years, and rather precise descriptions are available, although still controversial. ${ }^{2}$ It is commonly accepted that they are roughly spherical, core-shell particles, with outer diameters ranging from 50 to 500 $\mathrm{nm} \cdot{ }^{3-5}$ The core is now generally described as a homogeneous web of caseins in which calcium phosphate nanoclusters are uniformly distributed. ${ }^{6-8}$ The shell is essentially made of $\kappa$-caseins that extend into the aqueous phase as a polyelectrolyte brush and in this way produce short range repulsions between micelles. ${ }^{9,10}$

Even if the structure and composition of the casein micelle itself are now reasonably known, little has been done in understanding how these objects actually interact with each other and how these interactions influence the properties of native casein dispersions. In particular, we still need to understand how interactions and properties evolve when casein dispersions are concentrated, as for instance, in industrial operations like membrane filtration, ${ }^{11}$ evaporation and drying. ${ }^{12}$ In a recent study, we used the osmotic stress technique to explore interactions in model dispersions of casein micelles over a wide range of casein concentrations, i.e. from 20 to 500 $\mathrm{g} / \mathrm{L} .{ }^{13}$ Our results could be described in terms of three compression regimes: (1) a dilute regime in which the casein micelles are well separated and do not interact; (2) a transition regime in which the behavior of the dispersion changes from liquid-like to solid-like behavior as a result of 
the onset of interactions between micelles; (3) a concentrated regime in which the dispersions behave as coherent solids made of micelles that are in direct contact with their neighbors.

In this paper, we present measurements of the rheological properties of casein micelle dispersions in these three concentration regimes. First, steady shear viscosities were measured with casein micelle dispersions that "flow", i.e. dispersions that do not behave as solids (regimes 1 and 2). Second, oscillatory experiments were done to measure the complex shear modulus of dispersions over a large range of concentration, i.e. from diluted dispersions to highly concentrated dispersions obtained through osmotic stress (regimes 1 to 3). Additionally, creep-recovery tests were performed with some highly concentrated samples. For comparison, similar experiments were performed with sodium caseinate (SC) dispersions in the same range of casein concentrations. Even if they contain the same relative amount of caseins, SC dispersions are indeed quite different from casein micelle dispersions, with respect to structure ${ }^{14-16}$ and interactions. $^{13,17}$

To our knowledge, the rheology of casein micelle dispersions has never been investigated in this way. First, the dispersions were made from native phosphocaseinate powder (NPC) dissolved in a solvent made from ultrafiltration of skimmed milk (UF permeate). Casein micelles are very close to their native state in such a reconstituted milk that is depleted of serum proteins. ${ }^{18,19}$ Then, the dispersions were concentrated through osmotic stress using the same UF permeate with added hydrophilic polymers to control the chemical potential of water. This equilibrium ensured that the chemical potentials of all ions were identical to their values in milk. These features are quite different from previous works in which water was used a solvent ${ }^{20}$ or serum proteins were still present in the dispersions. ${ }^{21,22}$

The aim of this work is to provide some answers to the following questions:

\section{(i) Resistance to flow at concentrations below or near the liquid-solid transition:}


In this regime, do the micelles only interact through excluded volume effects? What are the consequences of these interactions for the resistance to flow of the dispersions: does it match that of a polydisperse hard sphere fluid? What is the effect of the fact that casein micelles are highly hydrated structures that can be deformed by compressive or shear forces?

These questions have already been raised by other authors ${ }^{4,21,23}$ but quantitative answers are still missing. Recent work performed by Alexander et al. through diffusing wave spectroscopy suggests that fat-free milk does behaves like a hard sphere system in a certain range of casein concentrations. $^{24}$

\section{(ii) Resistance to deformation at the liquid-solid transition and above:}

In this regime, can we still describe dense casein micelle dispersions as fluids of hard spheres? What are the forces that cause the resistance to deformation? Are they the same forces that produce the resistance to osmotic compression? ${ }^{13}$ Is there any involvement of intermicelle adhesion?

\section{EXPERIMENTAL}

\section{A. Materials}

All experiments were performed with dispersions made from casein powders (NPC, SC), dispersed in a solvent obtained through ultrafiltration of skimmed milk (UF permeate). We made this choice for the following reasons. First, the use of the UF permeate ensures that the chemical potentials of all ions are maintained to their values in the native state. Second, these casein powders are depleted of milk serum proteins that could interfere with rheological measurements and also with the preparation of concentrated samples through osmotic stress. Third, NPC powder is considered as an adequate model for milk casein micelles (see Huppertz et al. ${ }^{25}$ and MüllerBuschbaum et $\mathrm{al}^{26}$ for recent examples of its use). In contrast, SC powder contains the same 
relative amounts of caseins as NPC but does not lead to dispersions of stable "casein micelles". Instead, SC dispersions contain caseins that are present as individual molecules or as reversible self-assembled aggregates of radius $\sim 10 \mathrm{~nm} .{ }^{14-16}$

The NPC powder was prepared in our laboratory according to a protocol developed by Pierre et al. ${ }^{18}$ and Schuck et al. ${ }^{27}$ and described in our previous work. ${ }^{13}$ The SC powder was produced by Armor Protéines (Saint-Brice en Coglès, France) according to a protocol similar to that described by Segalen et al. ${ }^{28}$ In both powders, the caseins and their associated minerals represent more than $90 \%$ of the total solid content. The detailed compositions of the powders have been reported. ${ }^{13}$

The UF permeate was prepared through membrane ultrafiltration (5000 Da cutoff) of a fresh skimmed milk. Its approximate ionic composition is: $\sim 20 \mathrm{mM} \mathrm{Na}^{+}, \sim 40 \mathrm{mM} \mathrm{K}^{+}, \sim 10 \mathrm{mM} \mathrm{Ca}^{2+}$, $\sim 30 \mathrm{mM} \mathrm{Cl}^{-}, \sim 10 \mathrm{mM}$ phosphate, $\sim 10 \mathrm{mM}$ citrate and traces of carbonate, sulfate and magnesium ions (see Jenness and $\mathrm{Koops}^{29}$ for a full description). It also contains lactose $(\sim 150 \mathrm{mM})$ and a few other low molar mass molecules such as riboflavin, a vitamin that gives it a distinctive yellow color. Thimerosal and sodium azide, both purchased from Sigma-Aldrich, were added to the UF permeate as preservatives at $0.02 \%$ and $0.1 \%(\mathrm{w} / \mathrm{w})$ respectively.

\section{B. Sample preparation}

For casein concentration up to $170 \mathrm{~g} / \mathrm{L}$, the NPC and SC dispersions were prepared by thoroughly mixing the powders in UF permeate for $15 \mathrm{~h}$ at $35^{\circ} \mathrm{C}$ and $50^{\circ} \mathrm{C}$, respectively. Dispersions at higher casein concentrations were prepared through osmotic stress; a concentration technique which is based on water exchange between the sample (i.e., a liquid NPC or SC dispersion) and a reservoir of controlled osmotic pressure (see our previous work ${ }^{13}$ for a full description). This reservoir is generally a polymer solution: poly(ethylene glycol) with a molar mass of $35,000 \mathrm{Da}$ (Fluka, Switzerland) was used in our case. We measured the osmotic pressures of solutions of 
this polymer at concentrations up to $20 \%(\mathrm{w} / \mathrm{w})$ at $20^{\circ} \mathrm{C}$ through membrane osmometry (Osmomat 090, Gonotec, Germany) and equilibrium dialysis versus T110 Dextran solutions of known osmotic pressure. ${ }^{30}$ The results were fitted to the following expression for the osmotic pressure $\Pi(\mathrm{Pa})$ as a function of PEG concentration $[\mathrm{PEG}](\%, \mathrm{w} / \mathrm{w})$ :

$\log \Pi=a+b[\mathrm{PEG}]^{c}$

where $a=0.49, b=2.5, c=0.24$

Standard regenerated cellulose Spectra/Por 2 dialysis bags with a molecular mass cutoff of 12,000-14,000 Da and a diameter of $29 \mathrm{~mm}$ were used (Spectrum Laboratories, Rancho Dominguez, CA $)$. Casein dispersions of moderate concentration $(\sim 100 \mathrm{~g} / \mathrm{L})$ were placed in the bags and immersed in the polymer solutions kept at $20^{\circ} \mathrm{C}$. The bags were then regularly refilled with casein dispersion until equilibrium was reached (about 30 days). This technique makes it possible to prepare a fair amount (about $40 \mathrm{~mL}$ per bag) of homogeneous samples with casein concentrations up to $400 \mathrm{~g} / \mathrm{L}$.

For both preparation methods, the casein concentrations in the samples were accurately determined after preparation through drying at $105^{\circ} \mathrm{C}$. For that purpose, the relation between total solid content and casein concentration in $\mathrm{g} / \mathrm{L}$ was initially determined over a wide range of concentrations with model dispersions. At $20^{\circ} \mathrm{C}$, the $\mathrm{pH}$ of all dispersions matched the average $\mathrm{pH}$ of milk, i.e. $\mathrm{pH}=6.7 \pm 0.1$.

\section{Rheology}

Flow measurements were performed with a Contraves Low-Shear 30 viscometer (Ruislip, UK) for dispersions for $\eta<0.01$ Pa.s and with a TA Instruments AR2000 rheometer (Guyancourt, France) for dispersions with higher viscosities. Both instruments were operated using a Couette 
geometry with inner and outer radii of 5.5 and $6 \mathrm{~mm}$ (Low-Shear) and 14 and $15 \mathrm{~mm}$ (AR2000) respectively. During all measurements, the sample was covered with a film of mineral oil to prevent evaporation. The viscosity of the UF permeate was measured at $20^{\circ} \mathrm{C}$ with the Contraves Low-Shear 30 viscometer and found to be $\eta_{\mathrm{s}}=1.2 \times 10^{-3} \mathrm{~Pa} . \mathrm{s}$.

Oscillatory shear measurements were performed with the AR2000 rheometer. Different geometries were used depending on the consistency of the samples. At moderate concentrations (below 250-300 g/L for NPC dispersions), the samples obtained through osmotic stress were soft gels so that a cone and plate geometry (radius $30 \mathrm{~mm}$ and angle $4^{\circ}$ ) was used. At higher concentrations (>300 g/L), the dispersions obtained through osmotic stress clearly behaved as solids and parallel plates with grooved surfaces were used. In such cases, the sample was cut in cylindrical pieces of $2 \mathrm{~cm}$ in diameter and $4 \mathrm{~mm}$ in width. It was then quickly transferred onto the lower plate and the upper plate was gently lowered until the sample filled the gap and a constant normal force was reached (about $0.2 \mathrm{~N}$ ). A closed cover set-up was used to prevent evaporation with both geometries. $G^{\prime}$ and $G^{\prime \prime}$ were first measured as a function of strain at a set frequency of 1 Hz. The frequency dependent response was then measured from 0.01 to $10 \mathrm{~Hz}$ at a given strain within the region of linear response.

Creep-recovery tests were performed with the AR2000 rheometer using parallel plates with grooved surfaces. Creep stress (10 Pa) was applied during $2 \mathrm{~h}$ and recovery (zero stress) lasted for $6 \mathrm{~h}$. Strain was recorded as a function of time and was converted into compliance $J(t)=$ $\operatorname{strain}(t) /($ creep stress). A closed cover set-up was used to prevent evaporation.

All rheological experiments were performed at a fixed temperature of $20^{\circ} \mathrm{C}$. Measurements were repeated 2 or 3 times, showing very good reproducibility within $\pm 10 \%$. 


\section{RESULTS AND DISCUSSION}

\section{A. Viscous flow before the liquid-solid transition. Casein micelles as hard spheres?}

Fig. 1 shows the shear rate dependence of the apparent viscosity for casein micelle (NPC) dispersions in UF permeate with casein concentrations ranging from 10 to $168 \mathrm{~g} / \mathrm{L}$. At concentrations below $\sim 100 \mathrm{~g} / \mathrm{L}$, the dispersions behaved as Newtonian fluids over the range of shear rates investigated. At higher concentrations, shear-thinning was clearly visible. Shear thinning at high shear rates is a common phenomenon. For the hard sphere fluid, it is caused by a transition from a regime where the particles have pure Brownian motions, at low shear rates, to a regime where their motions are determined by hydrodynamics, at high shear rates. This behavior can be described through a simple model originally developed by Krieger and Dougherty, ${ }^{31}$ in which the apparent viscosity $\eta$ depends solely on shear stress $\tau$ according to:

$\frac{\eta-\eta_{\infty}}{\eta_{0}-\eta_{\infty}}=\frac{1}{1+\tau / \tau_{\mathrm{c}}}$

where $\eta_{\infty}$ and $\eta_{0}$ are the high and low shear limiting viscosities, respectively, and $\tau_{c}$ the characteristic shear stress which characterizes shear thinning.

This model was successfully used by de Kruif et al. to analyze the viscosities of silica dispersions in cyclohexane. ${ }^{32}$ The fits shown in Fig. 1 indicate that our data are also perfectly described by this model. The reduction to a master curve, presented in Fig. 2, confirms that a single set of parameters $\eta_{0}, \eta_{\infty}$ and $\tau_{\mathrm{c}}$ suffices to describe the shear thinning at all concentrations. Accordingly, casein micelle dispersions made at concentrations below the liquid-solid transition must closely resemble hard sphere fluids.

The best-fit values of the characteristic shear stress $\tau_{\mathrm{c}}$ are plotted in Fig. 3 as a function of the volume fraction $\phi$ occupied by the casein micelles in the dispersions. This equivalent hard sphere 
volume fraction was estimated using a micelle voluminosity taken as $4.4 \mathrm{~mL}$ per gram of dry casein. ${ }^{4}$ In Krieger's model, the characteristic shear stress depends on the sphere radius $a$ through: $\tau_{\mathrm{c}}=k T / b a^{3}$

where parameter $b$ is usually comprised between 2-3 for hard spheres. ${ }^{32}$

Taking an average micelle radius $a=100 \mathrm{~nm}$, the $\tau_{\mathrm{c}}$ values we obtained for NPC dispersions imply $b \approx 1-3$; which is close to the value of the hard sphere system. Fig. 3 compares our results with those obtained by de Kruif et al. for silica spheres in cyclohexane. ${ }^{32}$ The two set of data show very similar $\tau_{\mathrm{c}}$ values ranging from 0.5 to $4 \mathrm{~Pa}$, essentially because the dimensions of the investigated objects are similar ( $78 \mathrm{~nm}$ for the silica spheres of de Kruif et al..$^{32}$ ).

As shown in Fig. 3 , $\tau_{\mathrm{c}}$ first increases with $\phi$. It has a clear maximum at $\phi \approx 0.62(\sim 140 \mathrm{~g} / \mathrm{L})$ and then decreases to vanishing values at $\phi \approx 0.8-0.85$. This behavior is quite similar to that of the hard sphere fluid. However, for monodisperse hard-spheres, the maximum in $\tau_{\mathrm{c}}$ is located at $\phi \approx$ 0.5 and $\tau_{\mathrm{c}}$ decreases to zero at $\phi \approx \phi_{\text {rcp }} \approx 0.64$, i.e. at the random close packing fraction of spheres $^{33}$ (Fig. 3). The observed shift in volume fractions for NPC dispersions could have two possible causes. First, the high polydispersity of casein micelle dispersions, usually measured between 30 and $40 \%,{ }^{4}$ could be responsible for this effect. Indeed, polydispersity would lead to higher values for the volume fraction at which the hard-sphere system has a disorder-order transition, i.e. the volume fraction at which $\tau_{\mathrm{c}}$ is maximum. In the same manner, the random close packing fraction $\phi_{\text {rcp }}$ is also known to increase with polydispersity. As an example, $\phi_{\text {rcp }} \approx 0.78$ when the polydispersity is $40 \%$, as opposed to $\phi_{\text {rcp }} \approx 0.64$ for the monodisperse hard-sphere fluid. ${ }^{34}$ Second, as reported by Russel et al., ${ }^{35}$ a similar shift is found with soft sphere systems. Accordingly, we could reasonably imagine that casein micelles start to deform at the onset of shear thinning, and thus behave as soft spheres in this hydrodynamic regime. 
Our data also show a remarkable variation of the viscosities with casein concentration. The relative high and low shear limiting viscosities, $\eta_{\mathrm{r}, \infty}=\eta_{\infty} / \eta_{\mathrm{s}}$ and $\eta_{\mathrm{r}, 0}=\eta_{0} / \eta_{\mathrm{s}}$, respectively, are plotted as a function of casein concentration and casein micelle volume fraction in Fig. 4, taking $\eta_{\mathrm{s}}=1.2 \times 10^{-3} \mathrm{~Pa} . \mathrm{s}$ for the viscosity of UF permeate at $20^{\circ} \mathrm{C}$. At low volume fractions $(\phi<0.35)$, for the hard sphere fluid, de Kruif et al. ${ }^{32}$ propose that $\eta_{\mathrm{r}, 0}$ varies with $\phi$ as:

$\eta_{\mathrm{r}, 0}=1+2.5 \phi+4 \phi^{2}+42 \phi^{3}$

Fig. 4 shows that our data correlate well with Eq. (4), giving further support to the correspondence between NPC dispersions and hard sphere systems. Then, above $\phi \approx 0.4-$ $0.45(\sim 100-110 \mathrm{~g} / \mathrm{L}$ of casein), the relative low shear limiting viscosity increases much faster. The hard sphere fluid also has a similar behavior upon approaching the glass transition; the divergence of $\eta_{\mathrm{r}}$ is usually modelled with Quemada's equation: ${ }^{32,35}$

$\eta_{\mathrm{r}}=\left(1-\phi / \phi_{\max }\right)^{-2} \quad$ or $\quad \eta_{\mathrm{r}}=\left(1-C / C_{\max }\right)^{-2}$

with $\phi_{\max , 0}=0.64$ and $\phi_{\max , \infty}=0.71$ for $\eta_{\mathrm{r}, 0}$ and $\eta_{\mathrm{r}, \infty}$, respectively.

In our case $\eta_{\mathrm{r}, 0}$ does not follows Eq. (5) with $\phi_{\max }=0.64$. As already suggested, this difference might be explained by the polydispersity of casein micelle dispersions. Indeed, the random close packing fraction $\phi_{\max , 0}=0.64$ relates to monodisperse dispersions of spheres, whereas for a $40 \%$ polydisperse hard sphere fluid it is $\phi_{\max , 0}=0.78 .{ }^{34} \mathrm{Fig} .4$ shows that the measured viscosities are located between these two extreme cases of monodisperse and $40 \%$ polydisperse hard spheres systems.

In contrast to $\eta_{\mathrm{r}, 0}$, the relative high shear limiting viscosity $\eta_{\mathrm{r}, \infty}$ increased steadily over the whole range of concentrations and did not diverge at the highest concentrations (Fig. 4). On the one hand, the polydispersity might explain this result since it would also affect the value of $\phi_{\max , \infty}$; 
thus shifting the divergence in $\eta_{\mathrm{r}, \infty}$ to volume fractions that were not reached in our experiments. On the other hand, this feature could also be interpreted as a slight deviation from the hard sphere fluid behavior. Indeed, high shear rates might cause the micelles to deform and align along the flow direction. Such increased shear thinning has been observed in model emulsions of soft droplets by Saiki et al. ${ }^{36}$

In order to better understand the role of structure and interactions on the flow properties of casein micelles, we also measured the same properties on solutions of sodium caseinate in which the caseins are not structured into micelles. Fig. 5 presents the shear rate dependence of the apparent viscosity for SC dispersions in UF permeate. For 119 and $125 \mathrm{~g} / \mathrm{L}$ of caseins, the range of shear rates was rather limited, because the flow became unstable at high shear rates. A comparison with Fig. 1 indicates that the flow behavior of SC was quite different from that of NPC. In particular, the flow was Newtonian over a much wider range of shear rates in SC dispersions. The corresponding low shear limiting viscosities are reported in Fig. 4 as a function of casein concentration. Clearly, the values of $\eta_{\mathrm{r}, 0}$ of SC dispersions are much higher (until $>2$ orders of magnitude) than those of NPC dispersions. All these differences in flow behavior may be explained through the loss of the peculiar structure of the casein micelle in SC dispersions. These dispersions then behave as an "ordinary" entangled polymer system. This assumption is in direct agreement with recent work which shows that SC presumably forms highly hydrated selfassembled aggregates of about 11 caseins and $\sim 10 \mathrm{~nm}$ in radius that are expected to overlap and interpenetrate at low concentrations (starting from $C>50 \mathrm{~g} / \mathrm{L}$ ). ${ }^{14}$

At low shear, the specific viscosity of SC dispersions, $\eta_{\mathrm{sp}}=\left(\eta_{0}-\eta_{\mathrm{s}}\right) / \eta_{\mathrm{s}}$ varies with casein concentration in a manner that is typical of polymer systems ${ }^{37,38}$ (Fig. 6). At concentrations below $80 \mathrm{~g} / \mathrm{L}$, there is a first regime in which the specific viscosity increases with $C^{5 / 2}$; this exponent is 
in between those expected for polymer solutions in the unentangled $\left(\eta \sim C^{5 / 4}\right)$ and entangled $(\eta \sim$ $C^{15 / 4}$ ) regimes. ${ }^{37,39}$ Then, at concentrations above $80 \mathrm{~g} / \mathrm{L}$, there is another regime in which the data follow an extremely steep power law $\eta \sim C^{15}$. This type of dependence is usually related to a "hyperentanglement" regime, in which entanglements are supplemented by some local attractions between the casein chains, ${ }^{40}$ as for associating polymers systems for instance. ${ }^{41,42}$

Finally, it is important to remark that the viscosities of SC in UF permeate are well above those reported by other authors ${ }^{17,43}$ for sodium caseinate in different solvents (Fig. 6). This discrepancy most likely originates from the presence of $10 \mathrm{mM}$ calcium ions in UF permeate, in contrast to the calcium free solvents used by these authors. It is indeed known that calcium ions produce strong attractive interactions between casein chains, ${ }^{44}$ which may explain the enhanced associative behavior of SC in UF permeate.

The results presented in this first part can be summarized as follows.

- Flow resistance of dispersions in which caseins are associated into micelles (NPC, "native" form). At low shear rates, casein micelle dispersions of concentrations below $170 \mathrm{~g} / \mathrm{L}$ behave qualitatively and quantitatively as polydisperse hard sphere fluids, suggesting that in these conditions the micelles interact through excluded volume effects only. This is fully consistent with the view that casein micelles interact through short-range repulsions produced by the $7 \mathrm{~nm}$ height $\kappa$-casein brush located at their surfaces. ${ }^{9,10}$ The analogy with hard sphere systems suggests a glass transition at $C \approx 150-180 \mathrm{~g} / \mathrm{L}$, a concentration range that agrees with our former observations based on osmotic pressure measurements. ${ }^{13}$ At high shear rates, the limiting viscosities did not diverge at the highest concentrations investigated. This behavior could be caused entirely by polydispersity. However, it might also be interpreted as a slight deviation from hard sphere fluid behavior, caused by the deformability of the micelles. 
- Flow resistance of dispersions in which caseins are not "organized" into such micelles (SC). These dispersions behave as a polymer solution over the range of concentrations investigated, with a hyperentanglement regime that starts above $80 \mathrm{~g} / \mathrm{L}$ of caseins. This is fully consistent with the latest characterizations of such systems. ${ }^{14,43}$

The differences between these two types of dispersions demonstrate the crucial importance of structure and interactions in determining the flow behavior of casein dispersions.

\section{B. Viscoelastic properties in the liquid-solid transition region and above. Casein micelles as deformable, compressible, and adhesive spheres?}

At concentrations above $C \approx 130 \mathrm{~g} / \mathrm{L}$, the NPC dispersions began to show some elastic properties. This viscoelastic behavior was characterized through two types of experiments at small strains: through the response to harmonic stresses, and through creep-recovery experiments (Fig. 7). Fig. 7(a) shows the frequency dependence of the elastic modulus $G^{\prime}$ and loss modulus $G^{\prime \prime}$ of NPC dispersions with casein concentrations ranging from 136 to $370 \mathrm{~g} / \mathrm{L}$. At the lowest concentration $(C=136 \mathrm{~g} / \mathrm{L}, \phi \approx 0.6)$, the dispersion behaved as a viscoelastic fluid, with $G^{\prime}$ and $G^{\prime \prime}$ scaling as $f^{2}$ and $f^{1}$, respectively. The strong frequency dependence persisted at the next concentration (161 $\mathrm{g} / \mathrm{L}, \phi \approx 0.71)$. Then, at $178 \mathrm{~g} / \mathrm{L}(\phi \approx 0.78)$, there was a crossover of $G^{\prime}$ and $G^{\prime \prime}$ at frequencies just below $0.01 \mathrm{~Hz}$, and the frequency dependence was much less, indicating a transition to another regime. At the higher concentrations $(210 \mathrm{~g} / \mathrm{L}$ and $370 \mathrm{~g} / \mathrm{L}), G^{\prime}$ and $G^{\prime \prime}$ varied only slightly on frequency and $G^{\prime}$ clearly dominated $G^{\prime \prime}$, meaning that the dispersions behaved primarily as viscoelastic gels. At these two high casein concentrations, the apparent volume fractions that can be estimated from the voluminosity of an uncompressed micelle $\left(4.4 \mathrm{~mL} \cdot \mathrm{g}^{-1}\right)$ are $\phi \approx 0.9$ and 1.6 
respectively, indicating that the applied osmotic stress forced the casein micelles to deform $(\phi>$ $\left.\phi_{\text {rcp }}\right)$ and deswell $(\phi>1)$.

In addition to oscillatory measurements, creep-recovery tests were performed with the NPC in UF at $370 \mathrm{~g} / \mathrm{L}$. A creep stress of $10 \mathrm{~Pa}$ was applied to the sample during $2 \mathrm{~h}$. Stress was then set to zero and the recovery period lasted for $6 \mathrm{~h}$. During the entire test, strain was recorded as a function of time and was transformed into compliance $J(t)=\operatorname{strain}(t) /$ (creep stress) (inset of Fig. 7(b)). We converted the $J(t)$ results to the frequency domain using a procedure described by different authors. ${ }^{45,46}$ The $G^{\prime}$ and $G^{\prime \prime}$ obtained in this way cover frequencies from $10^{-5}$ to $0.1 \mathrm{~Hz}$, and are in very good agreement with those obtained at higher frequencies from oscillatory experiments (Fig. 7(b)). However, they have a crossover point at very low frequency $\left(f \approx 3 \times 10^{-5}\right.$ Hz). This crossover shows that the NPC dispersion, even at this extreme casein concentration, does not behave as a true elastic gel with permanent connections. This is also demonstrated by the fact that the dispersion did not completely recover after stress was removed (inset of Fig. 7(b)), indicating plastic flow at very long time scales.

Fig. 8 gives the concentration dependence of the elastic moduli obtained at low $(f=0.01 \mathrm{~Hz})$ and high $(f=10 \mathrm{~Hz})$ frequencies. In both cases, $G^{\prime}$ dramatically increases over a narrow range of casein concentrations, from $\sim 145$ to $\sim 178 \mathrm{~g} / \mathrm{L}$. At the end of this concentration region, the values of $G^{\prime}$ measured at both frequencies have come much closer to each other, and at higher concentrations they remain in the same ratio. We take this change in frequency dependence at $C_{\max }=178 \mathrm{~g} / \mathrm{L}$ as the "gel point" of the dispersion. This point is also roughly the point of crossover between $G^{\prime}$ and $G^{\prime \prime}$ at both low and high frequencies (Fig. 7); another common, although not universal, ${ }^{47}$ definition of the "gel point". 
At $C>178 \mathrm{~g} / \mathrm{L}, G^{\prime}$ and $G^{\prime \prime}$ still grow with casein concentration but this increase is much less pronounced. At these concentrations, the magnitude of the high-frequency elastic modulus is then very close to that of the osmotic pressure (Fig. 8). This correspondence has already been observed in other systems that were concentrated through osmotic stress, most remarkably by Mason et al. ${ }^{48,49}$ The comparison of osmotic and mechanical results shows that for NPC dispersions there is a transition at $C_{\max }=178 \mathrm{~g} / \mathrm{L}$ between a low concentration, "liquid" regime where $G^{\prime}<<\Pi$ and a high concentration "gel" regime where $G^{\prime} \approx \Pi$.

We first consider the region where $C<C_{\max }$. In this regime, the strong frequency dependence of the viscoelastic moduli indicates that the resistance to hydrodynamic flow is still the dominant contribution to $G^{\prime}$ and $G^{\prime \prime}$. Calculations of the high-frequency elastic modulus of a hard sphere fluid $^{50}$ indicate a frequency dependence $G^{\prime} \sim f^{1 / 2}$ at high volume fractions, close enough to the experimental dependence which is $G^{\prime} \sim f^{2 / 3}$ at $C=161 \mathrm{~g} / \mathrm{L}$. Moreover, the magnitude of $G^{\prime}$ increases by 3 decades (at high frequency) at the end of this concentration regime. This is also the behavior expected from a hard sphere fluid, upon approaching the random close packing fraction where the concentration is so high so that particles can hardly move. Indeed, for systems such as silica spheres and emulsions, numerous experiments have shown that the high-frequency modulus $G^{\prime}$ increases steeply near the random close packing fraction. ${ }^{48-54}$ The inset of Fig. 8 reproduces the plateau values of the elastic modulus $G_{p}^{\prime}$ obtained by Mason et al. with emulsions. ${ }^{48,49}$ In the range of volume fractions $\phi=0.58$ to 0.64 , where the droplets are expected to behave as hard spheres, $G_{\mathrm{p}}^{\prime}$ increases in exactly the same way as observed here. There are only two differences between our results on casein micelles and Mason's results on monodisperse emulsions. Firstly, in casein dispersions, the steep increase of the $G^{\prime}$ occurs at higher volume fractions $(\phi=0.64-0.78$, Fig. 8) because NPC dispersions are polydisperse (about 40\%) and can 
pack more efficiently up to $\phi_{\text {rcp }} \approx 0.78 .{ }^{34}$ Secondly, experiments on casein micelles did not exactly reach the "plateau" limit $G_{\mathrm{p}}^{\prime}$ as defined by Mason et al.; most probably because casein micelles are smaller than emulsion droplets and consequently have faster motions. Once these differences are accounted for, both systems can be analyzed as concentrated hard sphere systems close to $\phi_{\text {rcp }}$, and their mechanical response can be calculated using classical hydrodynamics of hard sphere liquids. Fig. 9 compares G' measured in NPC dispersions with the predictions of Lionberger and Russel for concentrated dispersions of free draining hard spheres. ${ }^{50,55}$ This model recognizes that hydrodynamic interactions reduce the relative mobility of the spheres at high $\phi$, but neglects lubrication forces, which become significant at extremely high frequencies only. Since the measurements in NPC dispersions were performed at intermediate frequencies, the free draining model is expected to be sufficient. In fact, considering that the data were not obtained in the high frequency limit required by the model, and that no parameters have been adjusted, the agreement with the model is quite satisfactory.

We will now consider the region where $C>C_{\max }=178 \mathrm{~g} / \mathrm{L}$. In this regime, the much weaker frequency dependence of $G^{\prime}$ and $G^{\prime \prime}$ indicates that elastic forces are the dominant contribution to $G^{\prime}$ and $G^{\prime \prime}$. There are two possible sources of elastic resistance to deformation in this regime. The first is the resistance to deformation of the micelles themselves. Indeed, at $C>C_{\max }$, the estimated volume fraction that is occupied by the micelles is $>0.78$ which is the random close packing volume fraction for a $40 \%$ polydisperse fluid of spheres. ${ }^{34}$ Thus, we can reasonably assume that the micelles are in contact at the onset of this regime and then progressively deform and/or deswell as concentration increases. The assembly of compressed micelles may then behave as the compressed emulsions of Mason et al., which do have an elastic resistance to shear stresses, due to the elasticity of their interfaces. ${ }^{48,49}$ Mason et al. analyze this resistance through a "network 
spring model" in which the number of springs between neighboring emulsion droplets grows as $C-C_{\max }$, while the number of droplets per unit volume grows as $C$. The elastic modulus is then expected to grow as $C\left(C-C_{\max }\right)$ as the system is compressed beyond $C_{\max } \cdot{ }^{48}$ Surprisingly, this emulsion model matches the results obtained with casein micelles over 2 decades in $G^{\prime}$, both at high and at low frequency (solid lines in Fig. 10(a)). It is then interesting to examine whether the elastic resistance of compressed casein micelles could have a similar origin as that of compressed emulsions, i.e. a network of membranes that would be deformed by the compression and by applied shear stress. In this case, the storage modulus would scale as $\sigma / r$, where $\sigma$ would be the tension of the membranes and $r$ the radius of the micelles. Using the exact same expressions as Mason et al., ${ }^{48,49}$ we evaluate $\sigma=0.01 \mathrm{~N} / \mathrm{m}$, which is not unreasonable for a membrane that would surround the micelle and serve as an anchor to the $\kappa$-casein brush.

Alternatively, one may reject any such precise structural features, and try to analyze the behavior of compressed casein dispersions at $C>C_{\max }$ according to a general percolation model. In this case the elastic properties would be limited by the resistance of bonds between micelles. If the number of such bonds grows as the number of contact points per micelles, assuming to be linear in $\left(C-C_{\max }\right)$, then percolation theory predicts that the storage modulus should vary as $\left(C-C_{\max }\right)^{n} .^{56}$ This type of power law also fits the variation of the storage modulus $G^{\prime}$ with casein concentration (Fig. 10(a)). However, the exponent is $n=1.3$, whereas most experiments on physical gels yield exponents $\mathrm{n}$, in the range 2 to $3 .^{56}$ This lower value of the exponent for NPC dispersions may indicate that bonds are not created at random locations through the casein "gel", which is not surprising considering this "gel" is made of casein micelles. On the other hand, recent numerical simulations of random packings of "jamming" spherical particles also led to such low values of exponents $n$ (between 0.5 and $1^{57,58}$ ). 
An indication of this transformation to a gel phase through the creation of bonds between the micelles is the observation of the gel fraction after reswelling, i.e. the fraction of gel that did not redisperse after $\sim 15 \mathrm{~h}$ in UF under strong agitation. Indeed, the gel fraction increases continuously with casein concentration ${ }^{13}$ (Fig. 10(b)), further confirming that more bonds are formed upon compression. We found that the gel fraction also varies as $\left(C-C_{\max }\right)^{s}$ with $s \approx 0.5-1$; $s=1$ corresponding to the "ideal" case where the gel fraction increases linearly with the number of bonds per micelles. Even if reswelling experiments indicate that intermicelle bonds are still present after $\sim 15 \mathrm{~h}$, it is important to note that these junctions are probably not "permanent" as the NPC dispersions still "flow" at very long time scales (Fig. 7(b)).

In the same manner as in part A, it is interesting to compare the viscoelastic properties of NPC dispersions to sodium caseinate (SC) dispersions where the caseins are not structured into micelles. Fig. 11(a) shows the frequency dependence of $G^{\prime}$ and $G^{\prime \prime}$ of such SC dispersions at casein concentrations that are similar to those reported for NPC in Fig. 7(a), i.e. from 134 to 343 $\mathrm{g} / \mathrm{L}$. Clearly, the viscoelastic behavior of SC is quite different from that of NPC (see Figs. 7 and 11). Most remarkably, SC dispersions have moduli that were strongly dependent on frequency over the whole range of concentrations; whereas $G^{\prime}$ and $G^{\prime \prime}$ were almost frequency independent for NPC dispersions at $C \geq 210 \mathrm{~g} / \mathrm{L}$ (Fig. 7). Moreover, SC dispersions show the typical behavior of entangled polymer systems at all concentrations, with a clear crossover of $G^{\prime}$ and $G^{\prime \prime}$ at a frequency that shifts gradually to lower values as concentration increases. All these observations match those from authors who worked on comparable SC systems ${ }^{17,43}$.

Fig. 11(b) gives the concentration dependence of the elastic and loss moduli obtained at high frequency $(f=10 \mathrm{~Hz})$ for both SC and NPC dispersions. As we previously discussed, the NPC dispersion changes abruptly from a low-viscosity liquid to a viscoelastic gel in a very narrow 
range of casein concentrations ( $145-178 \mathrm{~g} / \mathrm{L})$. Conversely, the high-frequency $G^{\prime}$ and $G^{\prime \prime}$ of SC dispersions increase much more slowly with concentration. For entangled polymer solutions in good solvent, the usual variation of the "plateau" modulus $G_{\mathrm{p}}^{\prime}$ is a power law $C^{n}$ with an exponent $n \approx 2-2.3,{ }^{59,60}$ that is in agreement with the theoretical predictions of de Gennes ${ }^{61,62}(n=$ 9/4). For SC dispersions at $C<150 \mathrm{~g} / \mathrm{L}$, the high-frequency value of $G^{\prime}$ follows a much steeper power law where $G^{\prime} \sim C^{11}$ (Fig. 11(b)). Besides the fact that the $G^{\prime}$ values reported here are not strictly identifiable with "plateau" values (a limit that we did not reach in our experiments), this faster variation might originates from local attractions between casein chains that increase the resistance against deformation. The existence of such a "hyper-entanglement" regime was already suggested in the first part of this work when discussing the viscosity results of SC dispersions at $C>80 \mathrm{~g} / \mathrm{L}$ (Fig. 6). To some extent, these results are similar to those of English et al.$^{63}$ who also show a stronger concentration dependence $(n=3.2)$ of $G_{\mathrm{p}}^{\prime}$ in associating polymer solutions compared to "standard" polymers. Then, starting from $C \approx 150 \mathrm{~g} / \mathrm{L}, G^{\prime}$ starts to deviate from this $C^{11}$ power law and increases more slowly with $C$ (Fig. 11(b)), suggesting a crossover to another regime. This change in dynamic behavior is probably related to the progressive "gelation" of the system. Indeed, simple manipulation of the most concentrated SC samples $(C>300 \mathrm{~g} / \mathrm{L})$ produced by osmotic stress shows that they behave as elastic solids. ${ }^{13}$ Such a solid-like behavior at short time scales is also visible in Fig. 11(a) where the SC dispersion at $343 \mathrm{~g} / \mathrm{L}$ shows a predominant elastic character at high frequencies. On the other hand, and in contrast to NPC, the compression of SC dispersions is always fully reversible (there is no remaining gel fraction after reswelling ${ }^{13}$ ), suggesting that "gels" of SC are held together by weak connections with short lifetimes. All these observations further confirm that SC dispersions have features similar to those of reversibly associating polymer solutions: such solutions indeed show a reversible 
"gelation" transition with concentration and/or temperature, but still can easily evolve and transform through the breaking and rebuilding of connections. ${ }^{64,65}$

The results presented in this second part can be summarized as follows.

- Mechanical resistance of dispersions in which caseins are associated into micelles (NPC). Up to a casein concentration that matches the random close packing of a $40 \%$ polydisperse hard sphere fluid $\left(\phi_{\text {rcp }}=0.78, C \approx 178 \mathrm{~g} / \mathrm{L}\right), \mathrm{NPC}$ dispersions still behave qualitatively and quantitatively as polydisperse hard sphere fluids; this is in accordance with the viscosity results of part A. At higher concentrations, there is another regime in which casein micelles deform and deswell as concentration increases. In this regime, the NPC dispersions behave as elastic gels and their resistance to shear results from the formation of bonds between micelles, combined with the elastic properties of the micelles. At very long times, however, dense NPC dispersions creep under constant stress, indicating that these bonds between micelles may be non-permanent.

- Mechanical resistance of dispersions in which caseins are not associated into micelles (SC). These dispersions behave as associating polymer solutions over the whole range of concentrations. Starting from $150 \mathrm{~g} / \mathrm{L}$, they undergo a slow and reversible "gelation" transition where weak connections are involved. These connections are easily disrupted and do not withstand strong stress.

\section{CONCLUSIONS}

The rheological properties of native casein micelle dispersions (NPC) have been examined over a wide range of concentrations, from dilute liquid-like dispersions $(\sim 10 \mathrm{~g} / \mathrm{L})$ to dense solid-like dispersions obtained through osmotic stress (up to $\sim 400 \mathrm{~g} / \mathrm{L}$ ). Permanent flow and oscillatory shear measurements were conducted; the results were analyzed in details and compared with 
previous results on osmotic pressures and phase behavior of NPC dispersions. ${ }^{13}$ Accordingly, we can now propose the following answers to the questions raised in the introduction:

\section{(i) Resistance to flow at concentrations below or near the liquid-solid transition:}

In this regime, (below $\sim 170 \mathrm{~g} / \mathrm{L}$ ), and at low shear rates, the casein micelle dispersions behave qualitatively and quantitatively as the polydisperse hard sphere fluids. At high shear rates, a slight deviation from the hard sphere fluid behavior was observed, presumably caused by deformations of the micelles in the flow. In all cases, the flow properties indicate that the micelles are well separated from each other and interact through excluded volume effects only.

\section{(ii) Resistance to deformation at the liquid-solid transition and above:}

Starting from $C \approx 130 \mathrm{~g} / \mathrm{L}$, the NPC dispersions begin to show elastic properties. Below $\sim 178$ $\mathrm{g} / \mathrm{L}$, they behave as viscoelastic liquids with properties similar to those of polydisperse hard sphere systems. Accordingly, excluded volume effects are the cause of the resistance to deformation at these concentrations. At $C_{\max } \approx 178 \mathrm{~g} / \mathrm{L}$, a phase transition takes place, and the NPC dispersions start to behave as elastic gels with a storage and a loss modulus $G^{\prime}$ and $G^{\prime \prime}$ that are much less dependent on frequency and concentration. Since $C_{\max }$ corresponds to the random close packing of the micelles, we assume that the micelles are then forced to deform and deswell, as in the case of the concentrated emulsions studied by Mason et al. ${ }^{48,49}$ In this concentration regime, the shear resistance must result from the resistance to deformation of individual micelles, combined with the formation of bonds between the micelles. The involvement of such intermicelle adhesions is consistent with our former observations of a remaining gel fraction after reswelling of highly dense NPC dispersions. ${ }^{13}$ In this last concentration regime, the magnitude of the elastic modulus is very close to that of the osmotic pressure. This correspondence could indicate that the same forces produce the resistance of the NPC dispersions to both osmotic 
compression and shear deformation. The exact nature of these forces is not known at present, and is the aim of future work.

Additionally, the results obtained with "native" casein micelle dispersions have been compared to those obtained with sodium caseinate (SC) dispersions in which the caseins are not structured into micelles. Interestingly, the rheological properties of the SC dispersions were quite different from those of the "native" form and quite close to those of common "hyperentangled" or associative polymer solutions. This is further confirmation of the importance of structure in determining the rheological behavior of casein micelle systems. It also gives further support to the idea that the forces involved in intermicelle cohesion are structure-dependent forces that are disrupted when the micelles are dissociated.

\section{ACKNOWLEDGMENTS}

We thank J. Lefebvre for help in the treatment of the creep-recovery data, as well as R. Buscall and W. B. Russel for interesting discussions. We are also grateful to J. Fauquant, F. GarnierLambrouin, and P. Schuck from UMR1253 for preparing and providing us with the NPC powders and the UF permeate of skimmed milk. 


\section{REFERENCE LIST}

C. Holt, Adv. Protein Chem. 43, 63 (1992).

${ }^{2}$ D. S. Horne, Curr. Opin. Colloid Interface Sci. 11, 148 (2006).

${ }^{3}$ D. G. Dalgleish, P. A. Spagnuolo, and H. D. Goff, Int. Dairy J. 14, 1025 (2004).

${ }^{4}$ C. G. De Kruif, J. Dairy Sci. 81, 3019 (1998).

${ }^{5}$ D. J. McMahon and W. R. McManus, J. Dairy Sci. 81, 2985 (1998).

${ }^{6}$ D. S. Horne, Curr. Opin. Colloid Interface Sci. 7, 456 (2002).

' S. Marchin, J. L. Putaux, F. Pignon, and J. Léonil, J. Chem. Phys. 126, 045101 (2007).

${ }^{8}$ D. J. McMahon and B. S. Oommen, J. Dairy Sci. 91, 1709 (2008).

${ }^{9}$ C. G. De Kruif and E. B. Zhulina, Colloids Surf., A 117, 151 (1996).

${ }^{10}$ R. Tuinier and C. G. De Kruif, J. Chem. Phys. 117, 1290 (2002).

"G. Brans, C. G. P. H. Schroen, R. G. M. Van Der Sman, and R. M. Boom, J. Membr. Sci. 243, 263 (2004).

${ }^{12}$ P. Schuck, Lait 82, 375 (2002).

${ }^{13}$ A. Bouchoux, P. E. Cayemitte, J. Jardin, G. Gésan-Guiziou, and B. Cabane, Biophys. J. 96, 693 (2009).

${ }_{14}$ A. HadjSadok, A. Pitkowski, T. Nicolai, L. Benyahia, and N. Moulai-Mostefa, Food Hydrocolloids 22, 1460 (2008).

${ }^{15}$ J. A. Lucey, M. Srinivasan, H. Singh, and P. A. Munro, J. Agric. Food Chem. 48, 1610 (2000).

${ }^{16}$ S. J. Radford and E. Dickinson, Colloids Surf., A 238, 71 (2004).

${ }^{17}$ D. Farrer and A. Lips, Int. Dairy J. 9, 281 (1999).

${ }^{18}$ A. Pierre, J. Fauquant, Y. Le Graët, M. Piot, and J. L. Maubois, Lait 72, 461 (1992). 
${ }^{19}$ M. H. Famelart, F. Lepesant, F. Gaucheron, Y. Le Graet, and P. Schuck, Lait 76, 445 (1996).

${ }^{20}$ C. David, F. Pignon, T. Narayanan, M. Sztucki, G. Gesan-Guiziou, and A. Magnin, Langmuir 24, 4523 (2008).

${ }^{21}$ A. O. Karlsson, R. Ipsen, K. Schrader, and Y. Ardo, J. Dairy Sci. 88, 3784 (2005).

${ }_{22}^{22}$ J. Kromkamp, S. Rijnsent, R. Huttenhuis, K. Schroen, and R. Boom, J. Food Eng. 80, 257 (2007).

${ }^{23}$ D. S. Horne, Colloids Surf., A 213, 255 (2003).

${ }^{24}$ M. Alexander, L. F. Rojas-Ochoa, M. Leser, and P. Schurtenberger, J. Colloid Interface Sci. 253, 35 (2002).

${ }^{25}$ T. Huppertz, A. L. Kelly, and C. G. De Kruif, J. Dairy Res. 73, 294 (2006).

${ }^{26}$ P. Muller-Buschbaum, R. Gebhardt, S. V. Roth, E. Metwalli, and W. Doster, Biophys. J. 93, 960 (2007).

${ }^{27}$ P. Schuck, M. Piot, S. Méjean, Y. Le Graët, J. Fauquant, G. Brulé, and J. L. Maubois, Lait 74, 375 (1994).

${ }_{28}$ P. Segalen, M. Boulle, G. Gwozdz, in Laits et produits laitiers. 2. Les produits laitiers, transformations et technologies, edited by F. M. Luquet (Tec et Doc - Lavoisier, Paris, 1985), p. 147.

${ }^{29}$ R. Jenness and J. Koops, Neth. Milk Dairy J. 16, 153 (1962).

${ }^{30}$ C. Bonnet-Gonnet, L. Belloni, and B. Cabane, Langmuir 10, 4012 (1994).

${ }^{31}$ I. M. Krieger and T. J. Dougherty, J. Rheol. 3, 137 (1959).

${ }^{32}$ C. G. De Kruif, E. M. F. van Iersel, A. Vrij, and W. B. Russel, J. Chem. Phys. 83, 4717 (1985).

${ }^{33}$ J. G. Berryman, Phys. Rev. A 27, 1053 (1983). 
${ }^{34}$ W. Schaertl and H. Sillescu, J. Stat. Phys. 77, 1007 (1994).

${ }^{35}$ W. B. Russel, D. A. Saville, W. R. Schowalter, in Colloidal Dispersions (Cambridge University Press, Cambridge, 1989), p. 466.

${ }^{36}$ Y. Saiki, C. A. Prestidge, and R. G. Horn, Colloids Surf., A 299, 65 (2007).

${ }^{37}$ D. C. Boris and R. H. Colby, Macromolecules 31, 5746 (1998).

${ }^{38}$ S. Dou and R. H. Colby, Macromolecules 41, 6505 (2008).

${ }^{39}$ M. Rubinstein, R. H. Colby, and A. V. Dobrynin, Phys. Rev. Lett. 73, 2776 (1994).

${ }^{40}$ J. D. Ferry, in Viscoelastic Properties of Polymers (Wiley, New York, 1980), p. 509.

${ }^{4}$ T. Annable, R. Buscall, R. Ettelaie, and D. Whittlestone, J. Rheol. 37, 695 (1993).

${ }^{42}$ T. Annable, R. Buscall, and R. Ettelaie, Colloids Surf., A 112, 97 (1996).

${ }^{43}$ A. Pitkowski, D. Durand, and T. Nicolai, J. Colloid Interface Sci. 326, 96 (2008).

${ }^{4}$ J. M. Manski, L. E. van Riemsdijk, A. J. van der Goot, and R. M. Boom, Biomacromolecules 8, 3540 (2007).

${ }^{45}$ J. Lefebvre, Rheol. Acta 45, 525 (2006).

${ }^{46}$ W. Wolthers, D. van den Ende, V. Breedveld, M. H. G. Duits, A. A. Potanin, R. H. W. Wientjes, and J. Mellema, Phys. Rev. E 56, 5726 (1997).

${ }^{47}$ S. Mortimer, A. J. Ryan, and J. L. Stanford, Macromolecules 34, 2973 (2001).

${ }^{48}$ T. G. Mason, J. Bibette, and D. A. Weitz, Phys. Rev. Lett. 75, 2051 (1995).

${ }^{49}$ T. G. Mason, M. D. Lacasse, G. S. Grest, D. Levine, J. Bibette, and D. A. Weitz, Phys. Rev. E 56, 3150 (1997).

${ }^{50}$ R. A. Lionberger and W. B. Russel, J. Rheol. 38, 1885 (1994). 
${ }^{s 1}$ F. M. Horn, W. Richtering, J. Bergenholtz, N. Willenbacher, and N. J. Wagner, J. Colloid Interface Sci. 225, 166 (2000).

${ }^{{ }_{2}}$ I. T. Kim and P. F. Luckham, J. Colloid Interface Sci. 144, 174 (1991).

${ }^{s 3}$ T. G. Mason and D. A. Weitz, Phys. Rev. Lett. 75, 2770 (1995).

${ }^{54}$ A. Weiss, M. Ballauff, and N. Willenbacher, J. Colloid Interface Sci. 216, 185 (1999).

${ }^{55}$ G. Fritz, B. J. Maranzano, N. J. Wagner, and N. Willenbacher, Journal of Non-Newtonian Fluid Mechanics 102, 149 (2002).

${ }^{56}$ L. Guo, R. H. Colby, C. P. Lusignan, and A. M. Howe, Macromolecules 36, 10009 (2003).

${ }^{57}$ C. S. O'Hern, S. A. Langer, A. J. Liu, and S. R. Nagel, Phys. Rev. Lett. 88, 075507 (2002).

${ }^{s 8}$ C. S. O'Hern, L. E. Silbert, A. J. Liu, and S. R. Nagel, Phys. Rev. E 68, 011306 (2003).

${ }^{59}$ Y. H. Lin and J. H. Juang, Macromolecules 32, 181 (1999).

${ }_{60}^{6}$ Juliani and L. A. Archer, Macromolecules 35, 6953 (2002).

${ }^{6}$ R. H. Colby and M. Rubinstein, Macromolecules 23, 2753 (1990).

${ }_{62}$ J. D. Ferry, in Viscoelastic Properties of Polymers (Wiley, New York, 1980), p. 501.

${ }^{63}$ R. J. English, J. H. Laurer, R. J. Spontak, and S. A. Khan, Ind. Eng. Chem. Res. 41, 6425 (2002).

${ }^{64}$ S. K. Kumar and A. Z. Panagiotopoulos, Phys. Rev. Lett. 82, 5060 (1999).

${ }^{65}$ S. K. Kumar and J. F. Douglas, Phys. Rev. Lett. 87, 188301 (2001). 


\section{FIGURE CAPTIONS}

FIG. 1. Shear rate dependence of apparent viscosity for NPC dispersions in UF permeate. Casein concentrations from top to bottom: 168, 158, 146, 138, 121, 92, 56 and $10 \mathrm{~g} / \mathrm{L}$. The lines are fits to Eq. (2).

FIG. 2. Reduced viscosity $\left(\eta-\eta_{\infty}\right) /\left(\eta_{0}-\eta_{\infty}\right)$ vs. reduced shear stress for NPC in UF at $168 \mathrm{~g} / \mathrm{L}$ (open diamonds), $158 \mathrm{~g} / \mathrm{L}$ (closed inverted triangles), $148 \mathrm{~g} / \mathrm{L}$ (open triangles), $138 \mathrm{~g} / \mathrm{L}$ (closed circles) and $121 \mathrm{~g} / \mathrm{L}$ (open squares). The solid line is calculated through Eq. (2).

FIG. 3. Characteristic shear stress as a function of volume fraction for NPC in UF (closed squares). The volume fraction occupied by the casein micelles was estimated using a micelle voluminosity of $4.4 \mathrm{~mL} / \mathrm{g} .{ }^{4}$ For comparison, the characteristic shear stress for colloidal dispersions of $78 \mathrm{~nm}$ radius silica spheres in cyclohexane ${ }^{32}$ is also reported as a function of volume fraction (crosses). The solid and dashed lines are guides for the eye.

FIG. 4. Concentration dependence of the relative viscosity $\eta_{\mathrm{r}}$ at low shear $\left(\eta_{\mathrm{r}, 0}=\eta_{\mathrm{o}} / \eta_{\mathrm{s}}\right)$ for NPC in UF (solid squares) and SC in UF (shaded diamonds), and at high shear $\left(\eta_{\mathrm{r}, \infty}=\eta_{\infty} / \eta_{\mathrm{s}}\right)$ for NPC in UF (open triangles). The volume fraction occupied by the casein micelles (upper $\mathrm{x}$-axis) was estimated using a micelle voluminosity of $4.4 \mathrm{~mL} / \mathrm{g} .{ }^{4}$ The dotted line is calculated through Eq. (4). The solid and dashed lines are calculated through the Quemada's equation (Eq. (5)) with $\phi_{\max }$ $=0.64\left(C_{\max }=145 \mathrm{~g} / \mathrm{L}\right)$ and $\phi_{\max }=0.78\left(C_{\max }=178 \mathrm{~g} / \mathrm{L}\right)$, respectively. 
FIG. 5. Shear rate dependence of apparent viscosity for SC dispersions in UF permeate. Casein concentrations from top to bottom are 125, 119, 98, 83, 47 and $6 \mathrm{~g} / \mathrm{L}$.

FIG. 6. Concentration dependence of specific viscosity for SC in UF (solid diamonds), SC in pure water (open squares, $\mathrm{pH} 6.7, \mathrm{~T}=20^{\circ} \mathrm{C}$, data from Pitkowski et al ${ }^{43}$ ) and $\mathrm{SC}$ in phosphate buffer $+0.1 \mathrm{M} \mathrm{NaCl}$ (open triangles, $\mathrm{pH} 6.8, \mathrm{~T}=25^{\circ} \mathrm{C}$, data from Farrer and Lips ${ }^{17}$ ). The dashed and solid lines have slopes $5 / 2$ and 15 respectively.

FIG. 7. (a) Frequency dependence of the elastic, $G^{\prime}$ (solid symbols), and loss, $G^{\prime \prime}$ (open symbols) moduli for NPC dispersions in UF permeate at different casein concentrations. The lines are guides for the eye. (b) Frequency dependence of the $G^{\prime}$ and $G^{\prime \prime}$ for NPC in UF at $370 \mathrm{~g} / \mathrm{L}$ : data from oscillatory experiments (inverted triangles); data from creep-recovery experiments (diamonds). The lines are guides for the eye. The inset shows the results of creep-recovery experiments in terms of compliance $J$ vs. time.

FIG .8. The low- ( $f=0.01 \mathrm{~Hz}$, triangles) and high- $(f=10 \mathrm{~Hz}$, squares) frequency elastic modulus $G^{\prime}$ of NPC in UF, as a function of casein concentration. The open circles are the osmotic pressures, $\Pi$, of the dispersions as measured by equilibrium dialysis. ${ }^{13}$ The upper $\mathrm{x}$-axis is the volume fraction occupied by the casein micelles in the dispersions, estimated using a micelle voluminosity of $4.4 \mathrm{~mL} / \mathrm{g} .{ }^{4}$ The filled area represents the $\phi=0.64-0.78$ region. The inset shows the scaled plateau elastic modulus $G_{\mathrm{p}}^{\prime}$ (crosses) reported by Mason et al. ${ }^{48,49}$ for monodisperse emulsions having radii from $0.25 \mu \mathrm{m}$ to $0.74 \mu \mathrm{m}$, and plotted as a function of $\phi$. The filled area represents the $\phi=0.58-0.64$ region. 
FIG. 9. The "hard sphere liquid" contribution to the elastic modulus of NPC dispersions. Experimental values of the storage modulus $G^{\prime}(\mathrm{f})$ at frequencies $f=0.1 \mathrm{~Hz}$ (open triangles) and $f$ $=10 \mathrm{~Hz}$ (filled triangles) as a function of $C / C_{\max }$ with $C_{\max }=178 \mathrm{~g} / \mathrm{L}$. The lines are calculated through the expressions given by Lionberger and Russel ${ }^{50}$ in the case of the hard sphere liquid (free draining model). Those calculations were made taking an average micelle radius of $\sim 100$ $\mathrm{nm}$ and a micelle voluminosity of $4.4 \mathrm{~mL} / \mathrm{g} .{ }^{4}$

FIG. 10. (a) The high $(f=10 \mathrm{~Hz}$, solid squares) and low $(f=0.01 \mathrm{~Hz}$, solid triangles) frequency elastic modulus, $G^{\prime}$, of NPC dispersions in UF as a function of $C-C_{\max }$ with $C_{\max }=178 \mathrm{~g} / \mathrm{L}(\phi \approx$ 0.78). The solid and dotted lines are fits to the models discussed in the text. (b) The remaining gel fraction in casein dispersions after reswelling in UF and plotted vs. $C-C_{\max }$ with $C$ the casein concentration before reswelling and $C_{\max }=178 \mathrm{~g} / \mathrm{L}(\phi \approx 0.78)$ (experiments are detailed in our previous work ${ }^{13}$ ). The solid lines are fits to the model discussed in the text.

FIG. 11. (a) Frequency dependence of the elastic, $G^{\prime}$ (solid symbols), and loss, $G^{\prime \prime}$ (open symbols) moduli for SC dispersions in UF permeate at casein concentrations similar to those of Figure 7. The lines are guides for the eye. (b) The high-frequency $\left(f=10 \mathrm{~Hz}\right.$ ) elastic, $G^{\prime}$ (solid symbols), and loss, $G^{\prime \prime}$ (open symbols) moduli of SC (triangles) and NPC (small squares) dispersions in UF as a function of casein concentration. The line has slope 11. 


\section{FIGURES}

FIG1

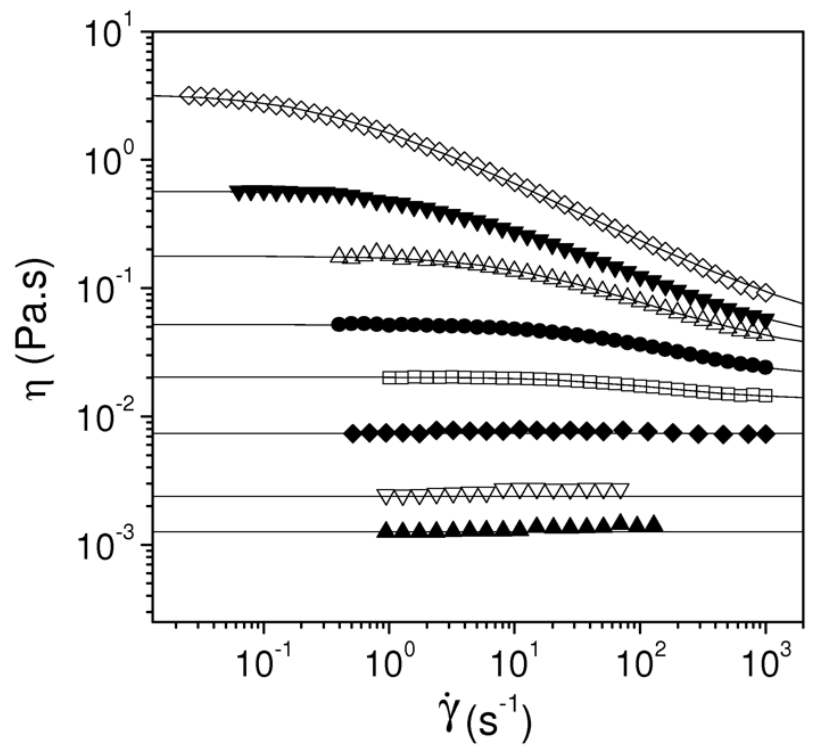




\section{FIG2}






\section{FIG3}






\section{FIG4}

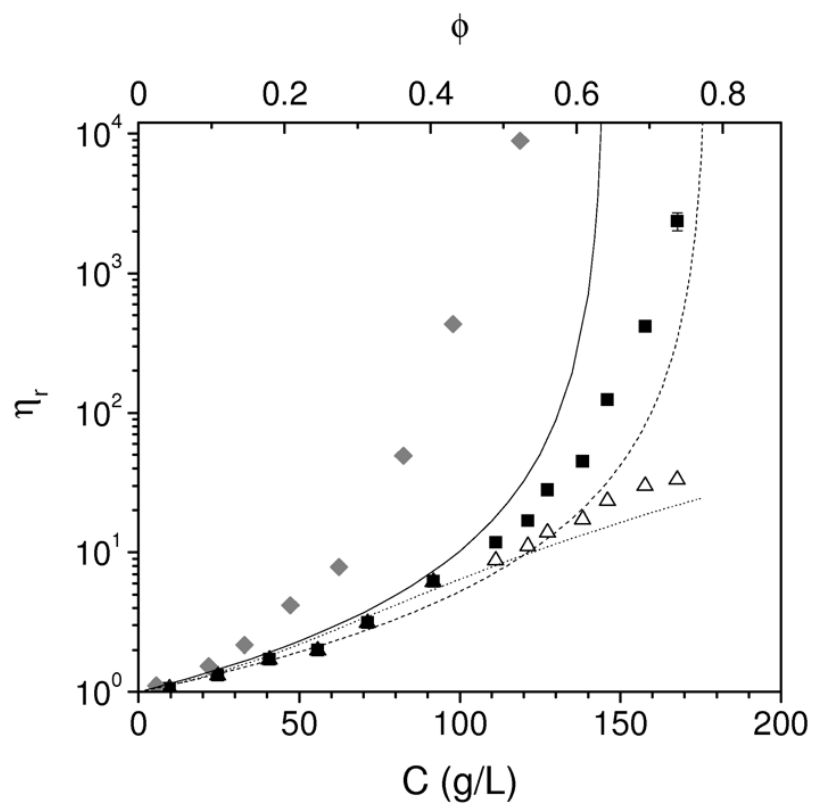




\section{FIG5}

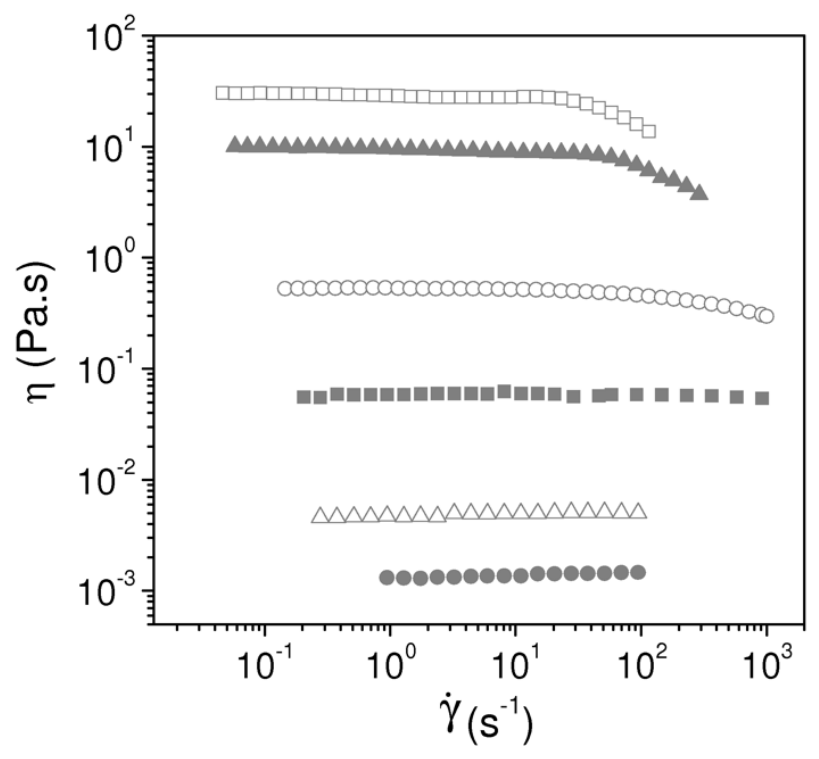




\section{FIG6}






\section{FIG7}
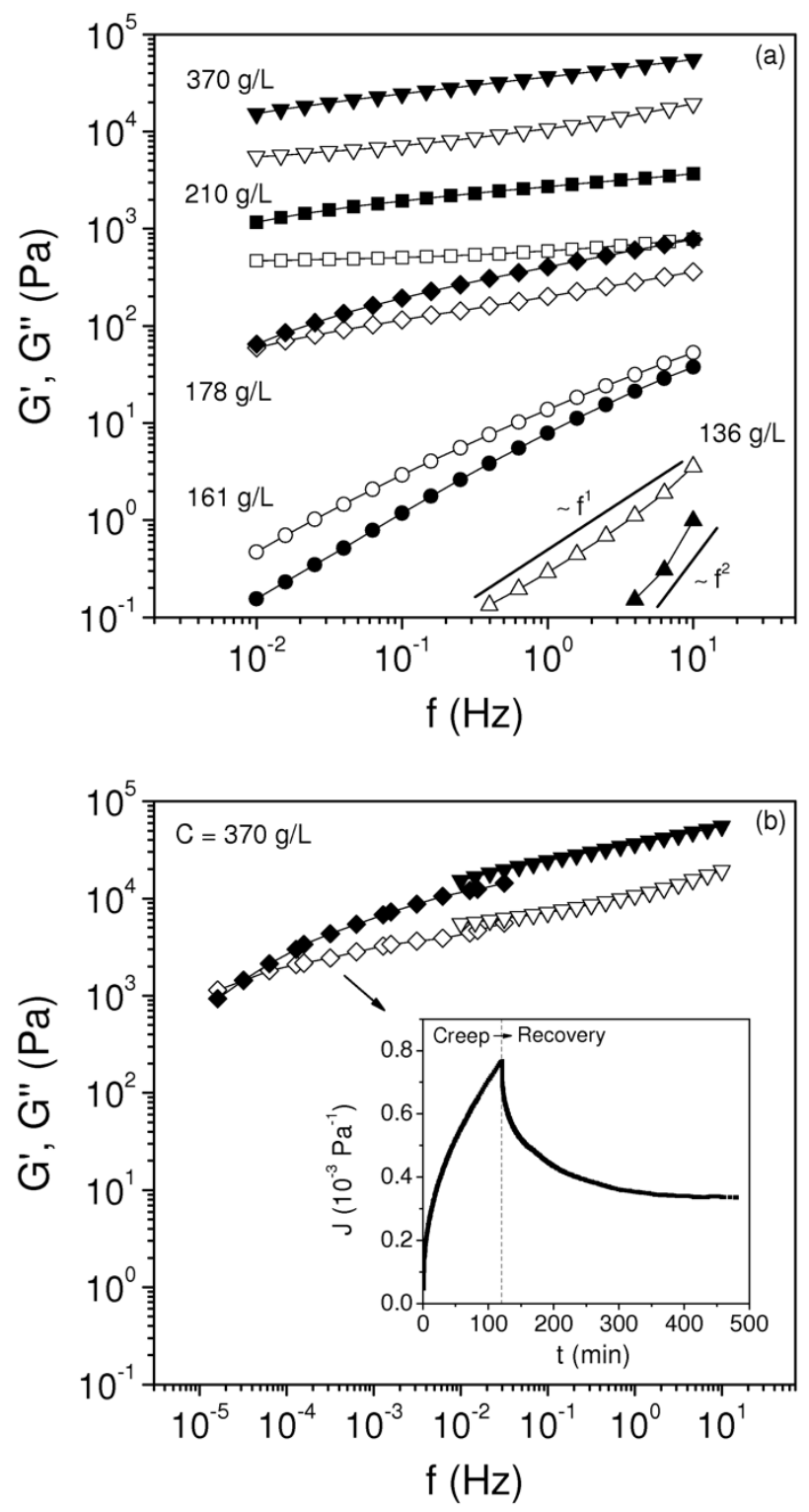


\section{FIG8}

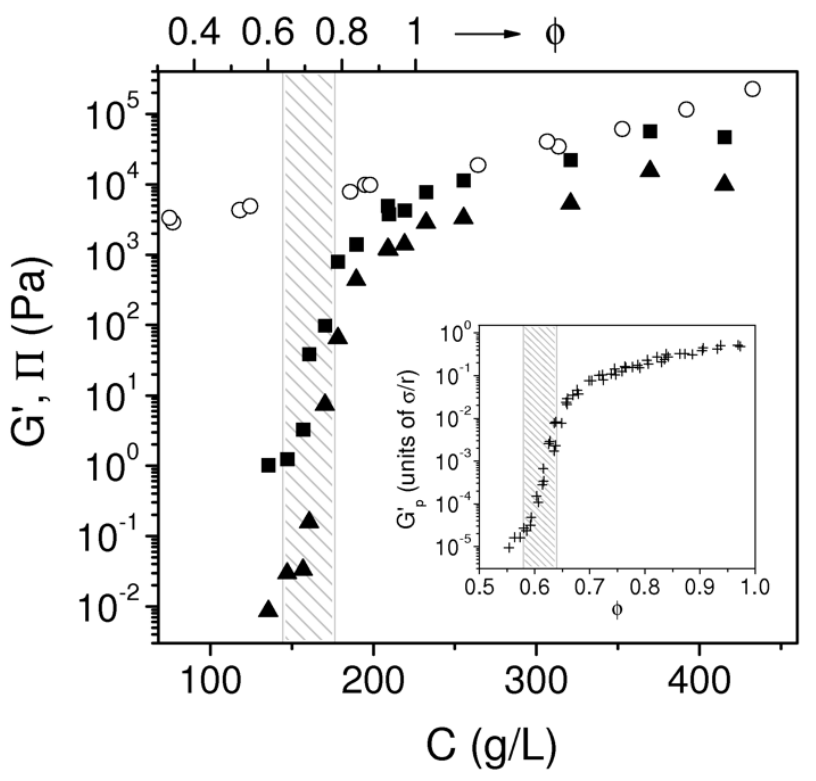




\section{FIG9}

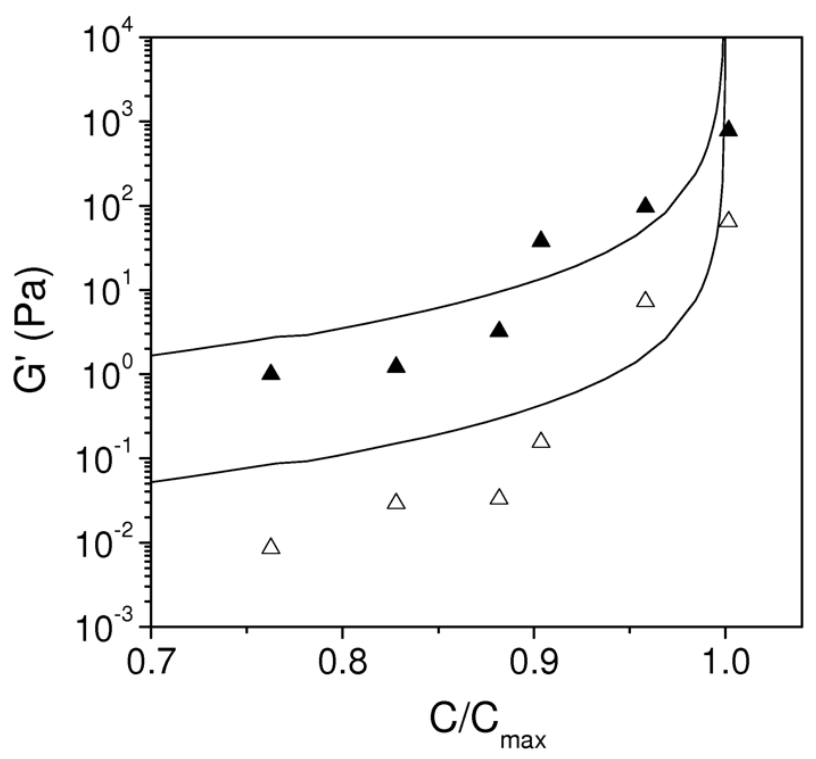




\section{FIG10}
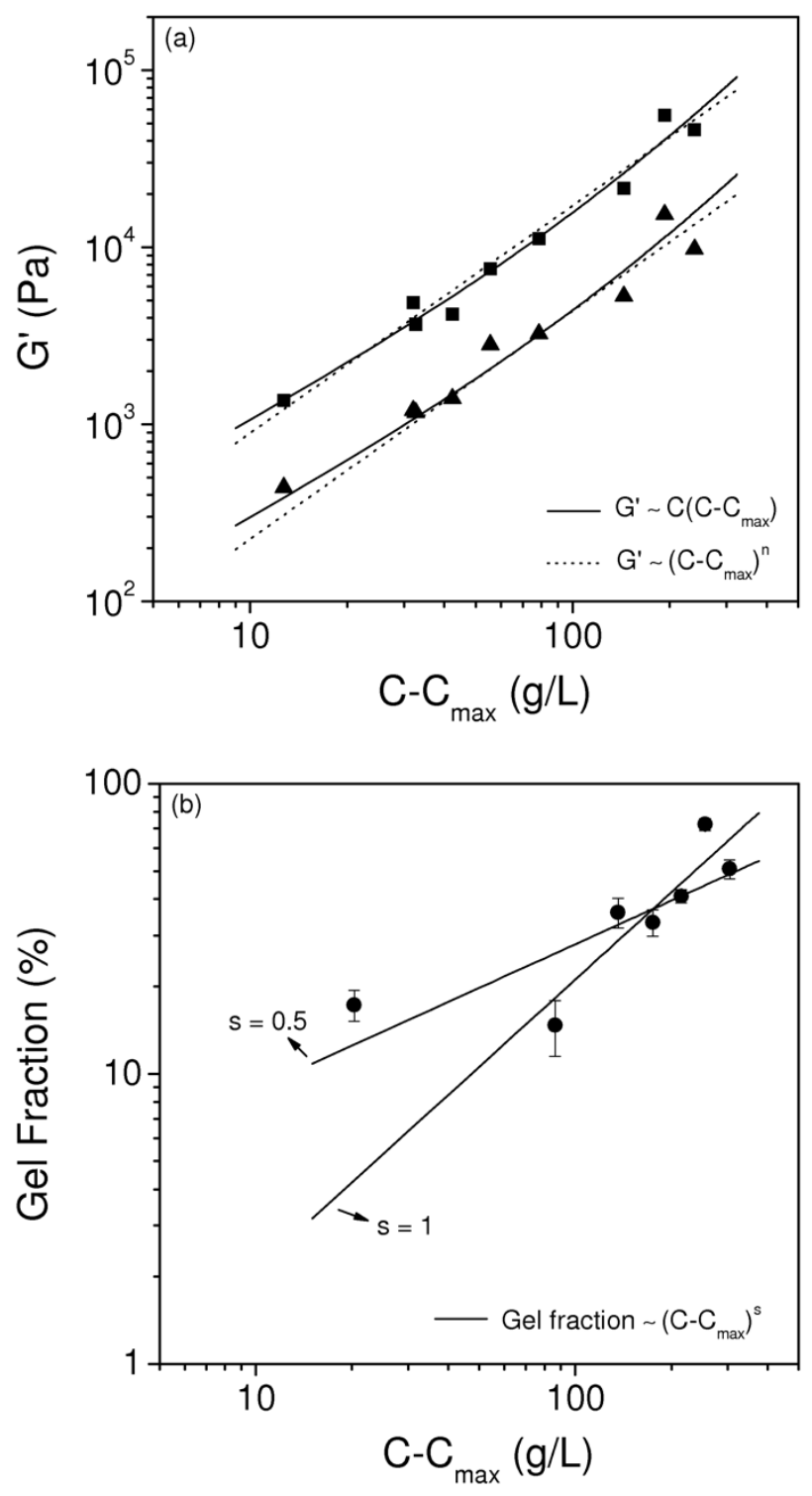


\section{FIG1 1}
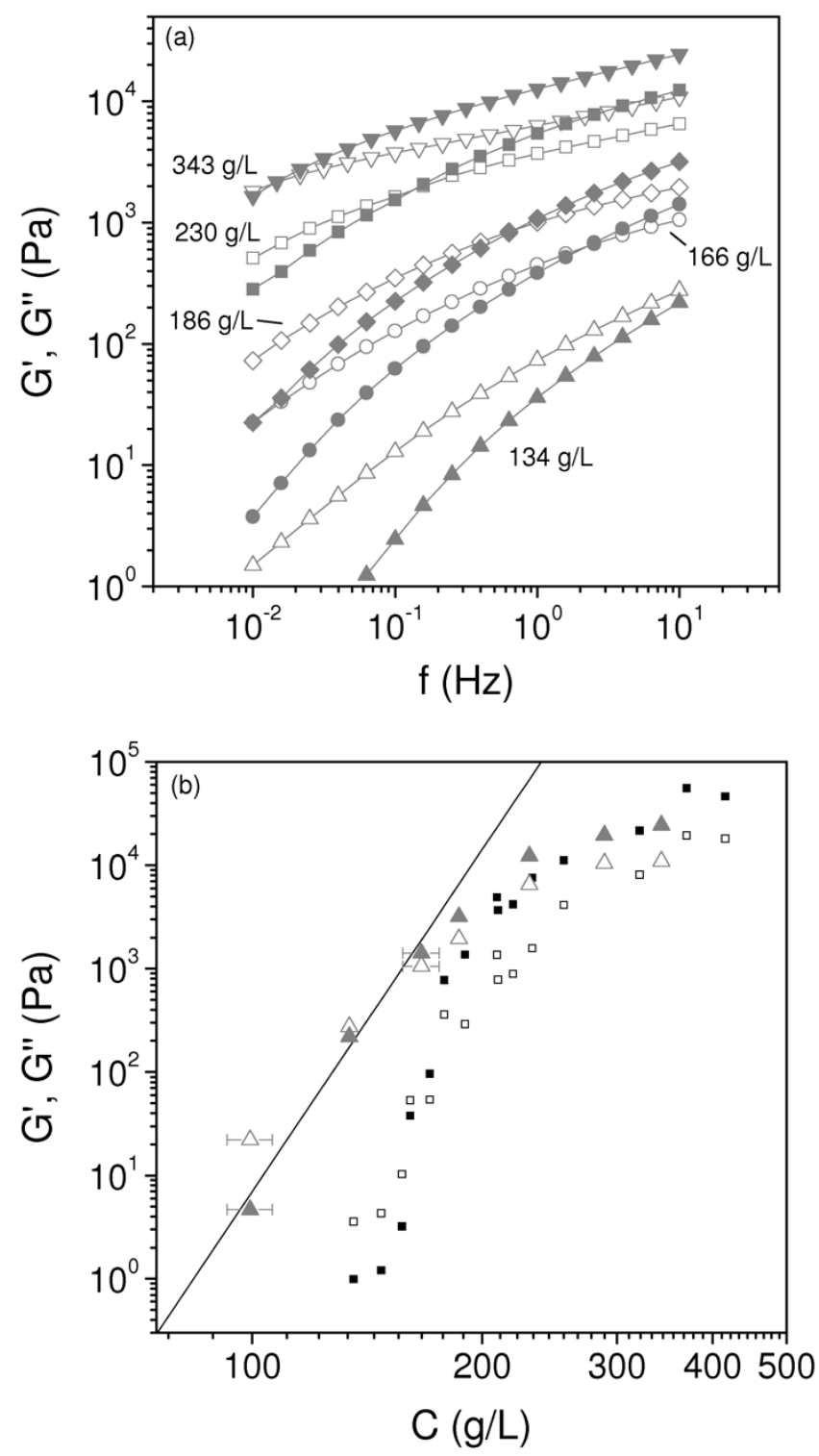